\title{
Fabrications of Effluence Free Fire Cracker using Pyrotechnic Chemical Composition
}

\author{
R. Manikandan, S. Rajesh
}

\begin{abstract}
The objective of the study is to increase the safety, health aspects in the workplace and to reduce the environment pollution which occurred during the burning of firecrackers by changing the chemical composition. The normal flash powder chemical composition used in firework industries are potassium nitrate (60\%), Aluminum (20\%), and sulfur (20\%). During the burning of pyrotechnic composition, it releases harmful gases and it leads to health effects to the human being and it pollutes the environment. Similarly, during the preparation of the cracker, workers are exposed by safety hazards. In this work, the mixing ratio of aforementioned chemical powders are changed and thermal analysis, sensitivity analysis like friction, impact and performance test like noise level of firecrackers are carried out for both existing chemical composition and modified chemical composition and it is compared.
\end{abstract}

Keywords- Pyrotechnic composition, TGA, Friction sensitivity, impact sensitivity, Noise level test

\section{INTRODUCTION}

$S_{\text {ivakasi is situated at the southern part of Tamilnadu. The }}$ main source of income for the people in forms the fireworks industry, match works and printing press industry, Study deals with the fireworks only. A few years back, only a small number of factories were producing crackers in the fireworks industry. Nowadays there are more than 500 factories catering to nearly $90 \%$ of the nation's need for fireworks. In fireworks, they have manufactured both ground level pyrotechnics like chakker, the atom bomb, bijili cracker, and fancy crackers, etc. Pyrotechnic are commercially used in all religions, cultures, and social occasions for expressing their pleasing throughout the world. [1] It is a class of explosive pyrotechnic materials which is used for wide varieties of occasions. A pyrotechnic composition is the combination of different chemical powders designed to produce heat, sound, light, and gases as a result of self-sustaining exothermic chemical reactions [4]. In India, it is more used on religious occasions and in other functions such as marriages. These firecrackers commonly produce the health and safety issues to the human being and environment. It is also a very sensitive material for handling and storage. There are so many examples which have already seen in the news about the crackers blast in storage areas. Fireworks are having sulfur as one of its

Revised Manuscript Received on December 5, 2019

* Correspondence Author

R.Manikandan, Department of Mechanical Engineering, Kalasalingam Academy of research and education, Krishnankoil-626126, India. Email: rmanikandan198@gmail.com

S.Rajesh*, Department of Mechanical Engineering, Kalasalingam Academy of research and education, Krishnankoil-626126, India. Email: s.rajesh@klu.ac.in ingredient which causes so many health defects to live beings as well as the environment. These facts lead us to the displacement of sulfur by the modified chemical mixture up to 10 percent which is a nature-friendly substance that can retard the harmful effects of sulfur up to an extent. The combustion of fireworks releases hot gases and it leads to health issues [2]

In pyrotechnic composition, Potassium nitrate $\left(\mathrm{KNO}_{3}\right)$, sulfur (S) and Aluminum ( $\mathrm{Al}$ ) are used as ingredients for making flash powder with different ratios like $60 \%, 20 \%$, and $20 \%$. Potassium nitrate act as an oxidizer, Aluminum act as a fuel and sulfur act as an igniter [3]. Here, the reduction of sulfur and it is balanced by aluminum metal powder and tests are carried out. Aluminum is also used as ingredients sparkler, flower pot, etc. The aluminum metal powders decomposed violently when adding of water content inappropriate level [5]. So water should be avoided with metal powders. The atmospheric conditions like temperature and humidity are also a reason for occurring of accidents. The artificial environmental chamber has been designed for storing the pyrotechnic chemical mixture and cracker for maintaining the temperature and humidity [6]. The environmental chamber is applicable for storing a small number of chemical powders only. The fireworks accidents and its cause's details are given in the Petroleum and Explosive Safety Organization (PESO) explosive report [7]. The bursting of ground-level pyrotechnics pollutes the atmospheric environment and affect human health [8]. Many numbers of fireworks accidents lead to fatality and property damage. [9].The objective of this work is to reduce the safety hazards during handling of pyrotechnic chemical mixtures and reduce the environment pollution during burning. The pyrotechnic composition is given in Fig. 1 and the various processes are involved in the manufacturing of firecracker. is given in Fig.2 


\section{Fabrications of Effluence Free Fire Cracker using Pyrotechnic Chemical Composition}

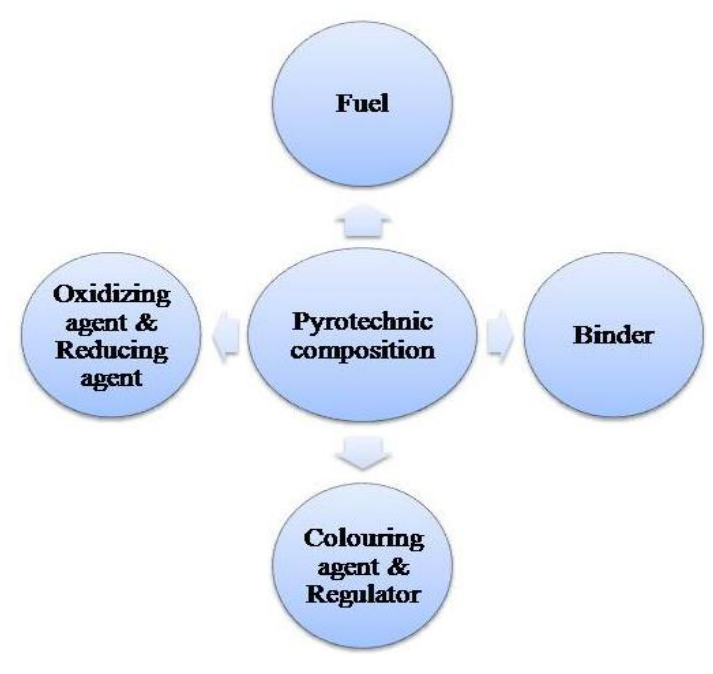

Fig. 1.Pyrotechnic composition

Preparation of chemical powder for sulfur, potassium nitrate, aluminium.

Weighing of all the aforementioned chemical mixture

Mixing the

Aforementioned chemical mixture.

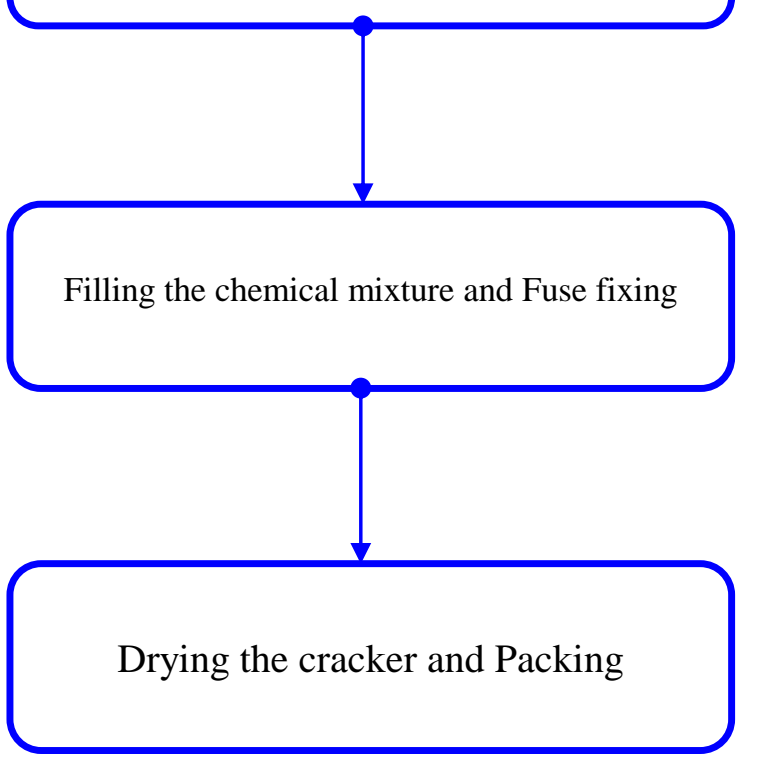

Fig. 2.The manufacturing process of firecracker

\section{A. Health effect of pyrotechnic chemical powders on the human being}

In the fireworks industry during the manufacturing of firecracker workers are exposed by chemical mixtures and they are suffered from the following health issues.

1.Neurological effects and behavioral change.

2.Disturbance of blood circulation.

3.Effects on eyes and problems in eye visibility.

4.Reproductive failure.

5.Damage to immune systems.

6.Stomach disorder.

7.Human liver and kidney functions are damaged.

8.Disturbance of the harmonic metabolism.

9.Dermatological effects.

10. Suffocation and lung embolism.

During the burning of the firecracker, the following issues are exposed by peoples.

\section{Hearing defects. \\ 2.Heart damage. \\ 3.Skin and burn injury.}

\section{MATERIALS AND METHODS}

In the fireworks industry, for preparing the firecracker the following ingredients used like sulfur, potassium nitrate and aluminium with a different ratio. All these chemical powders are obtained from local fireworks industries, Sivakasi, Tamilnadu. In this work, the aforementioned chemical composition, sulfur content is reduced by $5 \%$ and it is balanced by potassium nitrate and aluminum metal powder. The ratio of chemical powder is sulfur $-15 \%$, potassium nitrate $-62.5 \%$ and Aluminium $-22.5 \%$. The purity of $\mathrm{KNO}_{3}$ is $97.6 \%$. The purity of Aluminium and sulfur is $96 \%$ and $99.9 \%$. The size of the chemical powder is in a range of 45nanometer. After weighing the required amount of chemical powders it is allowed to sieving for removing the impurities, mixing for attaining the homogeneous mixture and thermal analysis, mechanical sensitivity like friction and impact tests are carried out for these chemical powders. Noise level is measured by using noise level meter (System824, Larson Davis Inc) during the bursting of cracker. So here, these chemical powders are filled into the paper tube and top of the tube is provided fuse and it is covered by a binding agent. Then a noise level test is carried out. The existing and modified chemical composition is compared using the aforementioned tests.

\section{A. EXPERIMENTAL TESTS}

Here, the experimental tests undergone involves the following tests, Thermal analysis, Noise level test, Impact sensitivity test and Friction sensitivity test. The thermal behavior of firecracker chemical mixture was analyzed by thermal analysis technique and it was conducted as per the standard procedure [10]

Published By:

Engineering \& Sciences Publication 
The noise level of the firecracker is monitored by using the sound level meter as per the standard regulations are given in Petroleum and Explosive Safety Organization (PESO) and the standard measurement procedure was followed [10].

The sensitivity analyses like friction and impact test are carried out as per the standard procedure [10]. Impact sensitive behavior of firework chemical mixture was analyzed by using the BAM method (impact sensitivity tester). The impact sensitivity has been decided by the limiting impact energy of chemical mixture. The limiting impact energy is calculated by mass of the object $(2 \mathrm{~g})$ which is fall down over the sample, gravity due to acceleration and at which height of the object is falling down. The friction sensitive of chemical powders are analyzed by using friction sensitivity tester and measurement has been taken as per the standard procedure. The impact and friction sensitivity setup are given Fig.3 \& 4.

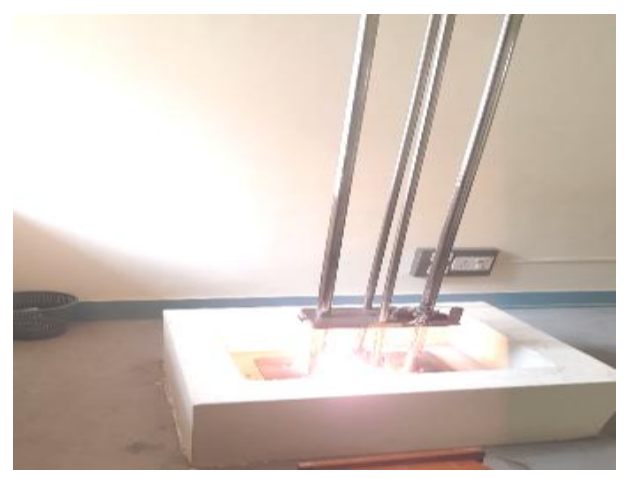

Fig. 3.Impact sensitivity Test

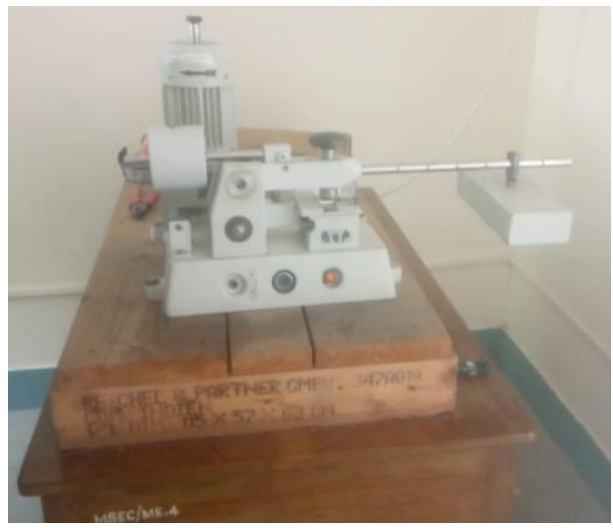

Fig. 4.Friction sensitivity test

\section{RESULT AND DISCUSSION}

It is observed from TGA test results of Heat flow with respect to temperature and weight loss, at $214.65^{\circ} \mathrm{C}$ the weight is reduced from $100 \%$ to $96.92 \%$. At $290.46^{\circ} \mathrm{C} 7.55 \%$ of the residue is evaporated and the weight percentage is $89.37 \%$. When the temperature is increased from $290.46^{\circ} \mathrm{C}$ to $489.86^{\circ} \mathrm{C}$, the residual loss is $2.34 \%$. At $647.56^{\circ} \mathrm{C}$, the residue evaporation percentage is $3.62 \%$. Final weight is $73.34 \%$. So, the total residue evaporation rate is $26.66 \%$. The residual percentage of normal chemical composition is $64.15 \%$. It is $9.19 \%$ lesser than the modified chemical composition. This residual amount can affect the performance of the firecracker. The generation of residue is reduced for modified chemical composition than the existing composition by changing the chemical composition. The TGA result of modified chemical composition is given in Fig.5.

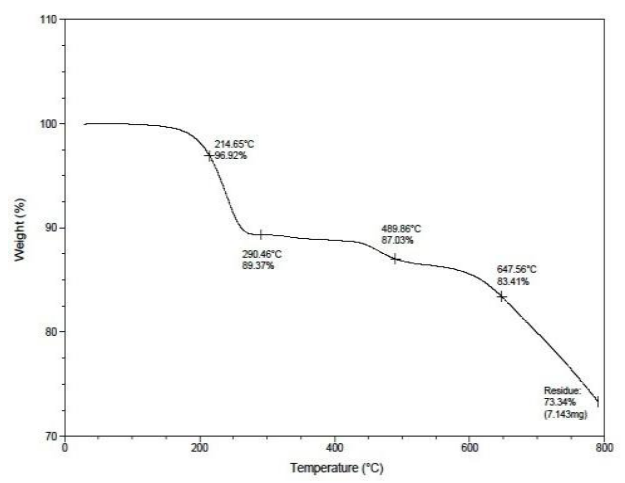

Fig. 5.TGA test result for modified composition

The result observed form friction sensitivity test, the sample does not have friction sensitiveness even at the maximum force of $360 \mathrm{~N}$. So it could be used as a safe firecracker. The result of friction sensitivity is given in Table. 1

It is observed from the impact sensitivity test, the limiting impact energy is less than 5joules. The value is 4.905joules and it is come under very sensitive. So the performance does not change. So the total result turns positive. The result of impact sensitivity is given in Table. 2

The result observed from noise level test, the sound level is below $125 \mathrm{~dB}$ which is legally acceptable by Noise Pollution Control Board and Environment Protection Act. The noise level result is given in Table. 3 .

Table-I: Friction sensitivity test result

\begin{tabular}{|c|c|c|c|c|c|c|c|}
\hline \multirow{2}{*}{$\begin{array}{c}\text { Flash powder } \\
\text { samples }\end{array}$} & \multicolumn{6}{|c|}{ Load in N } & \multicolumn{5}{|c|}{ Number of Trials } \\
\cline { 3 - 8 } & 360 & $\mathbf{1}$ & $\mathbf{2}$ & $\mathbf{3}$ & $\mathbf{4}$ & $\mathbf{5}$ & $\mathbf{6}$ \\
\hline \multirow{2}{*}{$\begin{array}{c}\text { Modified } \\
\text { chemical } \\
\text { mixture }\end{array}$} & 324 & $\mathrm{X}$ & $\mathrm{X}$ & $\mathrm{X}$ & $\mathrm{X}$ & $\mathrm{X}$ & $\mathrm{X}$ \\
\cline { 2 - 8 } & & $\mathrm{X}$ & $\mathrm{X}$ & $\mathrm{X}$ \\
\hline
\end{tabular}

Table-II: Impact sensitivity test result

\begin{tabular}{|c|c|c|c|c|c|c|c|c|}
\hline \multirow{2}{*}{$\begin{array}{c}\text { Load } \\
(\mathbf{m}) \text { in } \\
\mathbf{k g}\end{array}$} & $\begin{array}{c}\text { Height } \\
(\mathbf{h}) \\
\text { in m }\end{array}$ & $\mathbf{1}$ & $\mathbf{2}$ & $\mathbf{3}$ & $\mathbf{4}$ & $\mathbf{5}$ & $\boldsymbol{6}$ & $\begin{array}{c}\text { Limitin } \\
\text { g energy } \\
\text { in J }\end{array}$ \\
\hline 2.0 & 0.5 & $\checkmark$ & $\checkmark$ & $\checkmark$ & $\checkmark$ & $\checkmark$ & $\checkmark$ & 9.810 \\
\hline 2 & 0.45 & $\checkmark$ & $\checkmark$ & $\checkmark$ & $\checkmark$ & $\checkmark$ & $\checkmark$ & 8.829 \\
\hline 2 & 0.4 & $\checkmark$ & $\checkmark$ & $\checkmark$ & $\checkmark$ & $\mathrm{X}$ & $\checkmark$ & 7.848 \\
\hline 2 & 0.35 & $\checkmark$ & $\checkmark$ & $\mathrm{X}$ & $\boldsymbol{\checkmark}$ & $\checkmark$ & $\checkmark$ & 6.867 \\
\hline 2 & 0.3 & $\checkmark$ & $\checkmark$ & $\checkmark$ & $\mathrm{X}$ & $\checkmark$ & $\checkmark$ & 5.886 \\
\hline 2 & 0.25 & $\mathrm{X}$ & $\mathrm{X}$ & $\mathrm{X}$ & $\mathrm{X}$ & $\mathrm{X}$ & $\mathrm{X}$ & 4.905 \\
\hline
\end{tabular}

Table-III: Noise Level result

\begin{tabular}{|c|l|l|l|l|}
\hline & \multicolumn{1}{|c|}{$\begin{array}{c}\text { Specific } \\
\text { Modified } \\
\text { chemical } \\
\text { mixture }\end{array}$} & $\begin{array}{c}\text { Generated } \\
\text { noise level }\end{array}$ & $\begin{array}{c}\text { Specific } \\
\text { noise } \\
\text { limit }\end{array}$ & $\begin{array}{c}\text { Generate } \\
\text { d noise } \\
\text { level }\end{array}$ \\
\cline { 2 - 5 } & $125 \mathrm{dBA}$ & $<125 \mathrm{dBA}$ & $145 \mathrm{dBC}$ & $<145 \mathrm{dBC}$ \\
\hline
\end{tabular}




\section{Fabrications of Effluence Free Fire Cracker using Pyrotechnic Chemical Composition}

\section{CONCLUSION}

Thermos gravimetric analysis behavior of the modified chemical composition is studied and the following observation is made,

The generation of residue is comparatively higher for existing chemical composition than a modified chemical composition.

The observation is also made from impact sensitivity test, the limiting impact energy of both existing and modified chemical composition lesser than 5Joules and it comes under very sensitive. So the performance did not change. It is also observed from the friction sensitivity test, the frictional force is not created for both existing and modified chemical composition.

The noise result of modified chemical composition, the sound level produced below the standard noise level prescribed by the central government and it is below $125 \mathrm{dBA}$. So, the safety aspect has been improved for this modified composition. The environment pollution is also reduced when changing the chemical mixture and this kind of work makes our world is a green environment.

\section{REFERENCES}

[1] U.C. Kulshrestha et al., "Emissions and accumulation of metals in the atmosphere due to crackers and sparkles during Diwali festival in India". Atmospheric Environment, 38(27), 2004, pp. 4421-4425.

[2] C.Gouder, and S. Montefort, "Potential impact of fireworks on respiratory health. Lung India" : official organ of Indian Chest Society, 31(4), 2014, pp. 375-379.

[3] M.S.Russell, "The Chemistry of Fireworks." 2 ed, Cambridge, UK: RSC Publishing. 2009.

[4] S. Werrett, "Fireworks: pyrotechnic arts and sciences in European history." University of Chicago Press, 2010.

[5] A.V.SubbaRao, "Study of Decomposition of metal powders in wet pyrotechnic composition", proceeding of the National seminar , IIT Madras, 1999, pp.134-136.

[6] B.J. Huang, Y.C. Liao, T.C. Kuo,"Study of a new environmental chamber design,"Applied Thermal Engineering 27, 2007, pp.1967-1977

[7] "Petroleum and Explosive Safety Organization" Nagpur Accident report, Nagpur, 2003, pp 35-46

[8] G. Croteau, R.Dills., M.Beaudreau, \& M.Davis, "Emission factors and exposures from ground-level pyrotechnics". Atmospheric Environment, 44(27), 2010, 3295-3303.

[9] F.S Romolo, M.Aromatario, E.Bottoni, S.Cappelletti, P.A. Fiore, \& C.Ciallella, "Accidental death involving professional fireworks". Forensic science international, 234,2014, pp. e5-e9.

[10] A. Azhagurajan, N.Selvakumar, \& T.L. Thanulingam, " Thermal and sensitivity analysis of nano aluminium powder for firework application". Journal of thermal analysis and calorimetry, 105(1), 2011, pp. 259-267.

\section{AUTHORS PROFILE}

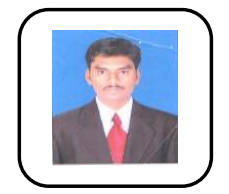

R.Manikandan obtained his B.E (MECH) in 2009 from the P.S.R Engineering College, Sivakasi, Tamilnadu, India. He completed his M.Tech (Industrial Safety Engineering) in 2014 at Mepco Schlenk Engineering College, Tamilnadu, India. Currently, he is working as a Assistant Professor in the Department of Mechanical Engineering, Kalasalingam Academy of Research and Education, Krishnankoil, Tamilnadu, India. His research interests include investigation of fireworks accidents and exposure of various experimental setup like frition, impact sensivity test, Noise level test and thermal analysis test.

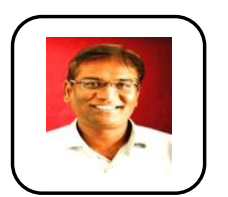

I have completed in B. E in Mechanical Engineering and M.E. (CAD) from Alagappa Chettiar Government College of Engineering and Technology, Karaikudi, $\mathrm{PhD}$ (Machining of Metal of Matrix Composites) from Kalasalingam Academy of Research and Education,

Krishnankoil in the year 2014, and thesis highly recommended by both the examiners. In the year 2018, I have received DST - AMT project for the worth of Rs 25, 72, 400 and completed one IEDC project for the worth of Rs 1, 00,000. I have published more than 25 journal papers (impact factor and Scopus cited) and more than 40 international conference papers. 